\title{
Neuroprotective Effect of Hydrogen-Rich Saline in Global Cerebral Ischemia/Reperfusion Rats: Up-Regulated Tregs and Down-Regulated miR-21, miR-210 and NF-kB Expression
}

\author{
Qian $\mathrm{Li}^{1}{ }^{1}$ - $\cdot$ Pan $\mathrm{Yu}^{2} \cdot$ Qiuting Zeng $^{3} \cdot$ Bing Luo $^{1} \cdot$ Shenquan Cai $^{1} \cdot$ Kangli Hui $^{1}$ • \\ Gao Yu ${ }^{1}$ Changsong $\mathrm{Zhu}^{1} \cdot \mathrm{Xingdong} \mathrm{Chen}^{1} \cdot$ Manlin Duan $^{1} \cdot \mathrm{Xuejun}_{\mathrm{Sun}^{4}}$
}

Received: 6 February 2016 / Revised: 1 May 2016 / Accepted: 9 June 2016 / Published online: 7 July 2016

(C) The Author(s) 2016. This article is published with open access at Springerlink.com

\begin{abstract}
Recently, it has been suggested that molecular hydrogen $\left(\mathrm{H}_{2}\right)$ can selectively reduce the levels of hydroxyl radicals $(. \mathrm{OH})$, and ameliorate oxidative and inflammatory injuries to organs in global cerebral ischemia reperfusion models. Global cerebral ischemia/reperfusion (I/R) can induce a sudden activation of inflammatory cytokines and later influence the systemic immunoreactivity which may contribute to a worse outcome. Regulatory T cells (Tregs) are involved in several pathological aspects of cerebral I/R. In addition, miRNA took part in the processes of cellular response to hypoxia. Since the expression of a specific set of miRNA called "hypoxamirs" is upregulated by hypoxia. Therefore, the aim of this study was to analyze the effect of HRS on I/R inducing cerebral damage, Tregs, and specific miRNA. Our results showed that rats undergone global
\end{abstract}

Qian Li and Pan Yu have contributed equally to this work.

Xingdong Chen

mengguren_cxd@163.com

$\checkmark$ Manlin Duan

dm19001@163.com

1 Department of Anesthesia, Jinling Hospital, No. 305, Zhongshan East Road, Nanjing 210002, Jiangsu, People's Republic of China

2 Department of Burn and Plastic Surgery, Jinling Hospital, No. 305, Zhongshan East Road, Nanjing 210002, Jiangsu, People's Republic of China

3 Department of Anesthesia, Zhongda Hospital, Southeast University, No. 87, Hunan Road, Nanjing 210002, Jiangsu, People's Republic of China

4 Department of Naval Aeromedicine, Faculty of Naval Medicine, Second Military Medical University, Shanghai 200433, People's Republic of China cerebral I/R and treated with HRS have milder injury than $\mathrm{I} / \mathrm{R}$ animals without HRS treatment. miR-210 expression in the hippocampus of the $\mathrm{I} / \mathrm{R}$ group at 6,24 and $96 \mathrm{~h}$ after reperfusion was significantly increased at each time point, while its expression in the group treated with HRS was significantly decreased. In addition, Tregs number in group $\mathrm{I} / \mathrm{R}$ was decreased at each time points, while its number in the group treated with HRS was increased at 24 and $96 \mathrm{~h}$ after reperfusion. We focus on the relationship among Tregs, TGF- $\beta 1$, TNF- $\alpha$ and NF- $\kappa B$ at $24 \mathrm{~h}$, and we found that there is a high correlation among them. Therefore, our results indicated that the brain resuscitation mechanism in the HRS-treated rats may be related with the effect of upregulating the number of Treg cells.

Keywords Global cerebral ischemia/reperfusion · Neuroprotection · Hydrogen - Regulatory T cells · MiRNA $\cdot$ Immuno-inflammatory response

\section{Introduction}

Global cerebral ischemia can cause severe central nervous system damage. However, the detailed mechanism is not fully known. Some studies suggest that activated immune cells can mediate the central nervous system injury and systemic immune inflammation, due to an early activation caused by acute cerebral ischemia and reperfusion [1]. These reactions are often accompanied by reactive oxygen species production, leading to NF- $\mathrm{KB}$ activation, which is involved in the activation of inflammatory gene promoters, and induction of inflammatory cytokines such as TNF- $\alpha$ [2]. Many studies have recently identified T lymphocytes as important mediators of ischemic brain damage, but the contribution of the different T-cell subsets is still unclear [3]. 
Tregs are a $\mathrm{CD} 4^{+}$subset, characterized by $\mathrm{CD} 25^{+}$expression, since immunoregulatory function is absent in $\mathrm{CD} 4^{+} \mathrm{CD} 25^{-}$ cells. Moreover, $\mathrm{CD} 4{ }^{+} \mathrm{CD} 25^{+} \mathrm{T}$ cells are characterized by a Forkhead box P3 (FOXP3) gene high expression, which is induced and sustained in Treg cells by TGF- $\beta$ signaling. $\mathrm{CD}^{+} \mathrm{CD}^{2} 5^{+} \mathrm{FoxP}^{+}$regulatory $\mathrm{T}$ cells (Tregs) are a component of the immune system that suppress immune responses of other cells, thus considered anti-inflammatory cells that maintain immune tolerance and counteract tissue damage in a variety of immune-mediated disorders [4]. Some studies demonstrated that Tregs infiltrate ischemic-reperfused organs during the healing process promoting repair, likely through modulation of pro-inflammatory cytokine production by other $\mathrm{T}$ cell subsets [5]. However, the role of Treg in the process of cerebral ischemia/reperfusion (I/R) has not been fully elucidated.

Hydrogen $\left(\mathrm{H}_{2}\right)$, an agent that has antioxidant and antiinflammatory properties, has been suggested as a potent free radical scavenger, since it selectively reduces the hydroxyl radical, the most cytotoxic radical among the reactive oxygen species [6, 7]. Indeed, many previous studies confirmed that hydrogen can effectively protect against tissue damage both in vivo and in vitro, including transient cerebral ischemia, neonatal cerebral hypoxia-ischemia, carbon monoxide toxicity, sepsis, traumatic brain injury, Parkinson's disease and myocardial injury induced by I/R; however, the possible mechanism and signaling pathway is unclear [8-12].

MicroRNAs are a class of endogenous $\sim 22 \mathrm{nt}$ noncoding RNAs that can regulate gene expression at a transcriptional and/or post-transcriptional level by indirect regulation of transcription factors, post-transcriptionally by inducing mRNA degradation, or directly inhibiting the translation [13]. Several studies have showed that miRNA expression profile in cerebral ischemia-reperfusion injury is significantly changed, suggesting their implication in this disease process [14-16]. Studies over the last few years have confirmed that there is a variety of miRNA expression on $\mathrm{T}$ cells. These miRNAs play an important role in the regulation of development, maturation, differentiation, function and various other aspects of $T$ cells growth. Activated $\mathrm{CD}^{+} \mathrm{T}$ cells and Treg miRNA expression profiles are very similar. The above mentioned miRNA are probably taking part in the regulation of nuclear transcription factor or other functional genes associated with activated T cells. Despite that, the miRNA specific function and role in the $\mathrm{CD}^{+} \mathrm{T}$ cells and Treg is unclear.

Numerous data suggest that hydrogen rich saline (HRS) could have a therapeutic effect on. I/R injury by involving anti-inflammatory and anti-oxidative mechanisms [9]. However, the effects of HRS on Treg and miRNA expression during I/R have not yet been reported. The present study provided evidence of HRS cerebroprotective effects in rats subjected to cerebral I/R injury, suggesting that HRS could be a novel therapeutic approach to enhance recovery from $\mathrm{I} / \mathrm{R}$ injury [17]. Moreover, we confirmed that the change of Treg, NF- $\kappa \mathrm{B}$ and miRNA expression was correlated with the $\mathrm{I} / \mathrm{R}$ injury degree and we analyzed their correlation. We also performed tests to evaluate TGF- $\beta 1$ and TNF- $\alpha$ concentration to confirm Treg modified content results.

\section{Materials and Methods}

\section{Animals and Groups}

The experimental procedures were carried out in accordance with the guidelines for the Care and Use of Laboratory Animals published by the US National Institute of Health (NIH Publication No. 85-23, revised 1996) and was approved by the Institutional Animal Care and Use Committee of Nanjing University and the Jinling Hospital, Nanjing, China. Male Sprague-Dawley rats, aged 7 weeks, weighting $280 \pm 20 \mathrm{~g}$, were purchased from the Experimental Animal Central of Jinling Hospital. All animals were housed under a $12 \mathrm{~h}$ light/dark cycle with constant temperature and free access to standard rodent chow and tap water. All rats were fasted for $12 \mathrm{~h}$ with water ad libitum before the operation.

In total, 123 rats were used. Three rats died during the operation. Among the 120 rats that survived, eight showed seizure after $15 \mathrm{~min}$ of ischemia thus, they were excluded from this study. Therefore, 112 rats were randomly divided into three groups: (1) sham group: sham operation (14 rats, $\mathrm{T}_{0}$ ); (2) sham $+\mathrm{H}_{2}$ group: sham operation plus HRS via intraperitoneal at the end of the operation (14 rats, $\mathrm{T}_{0}$, $0.16 \mathrm{~mol} / \mathrm{kg}$ ); (3) I/R group: 6 (14 rats, $\mathrm{T}_{1}$ ), 24 (14 rats, $\mathrm{T}_{2}$ ) and $96 \mathrm{~h}\left(14\right.$ rats, $\left.\mathrm{T}_{3}\right)$ ischemia reperfusion plus physiologic saline ( $5 \mathrm{ml} / \mathrm{kg}, \mathrm{I} / \mathrm{R})$; and (4) $\mathrm{H}_{2}$ group: 6 (14 rats, $\mathrm{T}_{1}$ ), 24 (14 rats, $\mathrm{T}_{2}$ ) and $96 \mathrm{~h}\left(14\right.$ rats, $\left.\mathrm{T}_{3}\right)$ ischemia reperfusion plus HRS $\left(0.16 \mathrm{~mol} / \mathrm{kg}, \mathrm{I} / \mathrm{R}+\mathrm{H}_{2}\right)$. Either physiologic saline or HRS was intraperitoneally injected immediately after reperfusion and $6 \mathrm{~h}$ after reperfusion, respectively. The physiologic saline and HRS was intraperitoneally injected over $5 \min [18,19]$.

\section{Global Cerebral I/R Model}

Global cerebral I/R was induced using the four-vessel occlusion (4-VO) method, as previously described [20-22]. Only rats that were unresponsive and lost the pupillary light reflexes after carotid artery occlusion were considered adequately ischemic. Animals that convulsed during and after the ischemic insult were not used in the experiments. The rectal temperature was maintained at $37^{\circ} \mathrm{C}$ using a homeothermic blanket during the whole experiment. The shamoperated rats underwent anesthesia and vertebral artery occlusion without the common carotid arteries occlusion. 


\section{HRS Preparation}

HRS was prepared as previously described [23] using an equipment provided by the Department of Diving Medicine, the Second Military Medical University, China. HRS was stored under atmospheric pressure at $4{ }^{\circ} \mathrm{C}$ in an aluminum bag with no dead volume and was sterilized by gamma radiation. Gas chromatography was used to confirm the hydrogen level content in the saline by the method described by Ohsawa et al. [24]. HRS was freshly prepared every week to ensure that the hydrogen concentration of more than $0.8 \mathrm{mmol} / \mathrm{L}$ was maintained.

\section{Behavioral Test}

To investigate the neurobehavioral manifestations after global cerebral I/R, Neurological Severity Scores (NSS) were evaluated in all the rats of each group at $\mathrm{T}_{0}, \mathrm{~T}_{1}, \mathrm{~T}_{2}$ and $\mathrm{T}_{3}$. The test was performed by inspectors blinded to the groups. According to the NSS, the neurological function was evaluated on a scale of 0-18: movement/activity (no spontaneous movement $=0$; sluggish movement $=1$; normal movement $=2$ ); respirations (irregular breathing pattern $=0$; decreased breathing frequency with normal pattern $=1$; normal breathing frequency and pattern $=2$ ); consciousness (no reaction to pinching of tail $=0$; poor response to tail pinch $=1$; normal response to tail pinch $=2$ ); coordination (failure in $1 \mathrm{~cm}$ wide beam balancing task and balances with steady posture, paws on top of beam $=1$; grasps sides of beam and/or has shaky movement $=1$; one or more paws slip off beam $=1$; attempt to balance on beam but falls off $=1$; drapes over beam and/or hangs on beam and falls off $=1$; falls off beam with no attempt to balance or hang on $=1$ ); and corneal reflex (no blinking $=0$; sluggish blinking $=1$; normal blinking $=2$ ). A score of 13-18 points indicates severe injury; 7-12 moderate injury; and 1-6 mild injury $[25,26]$.

\section{Preparation of Brain Slices in the CA1 Area of the Hippocampus}

The brain tissues of three rats in each group were harvested at $\mathrm{T}_{0}, \mathrm{~T}_{1}, \mathrm{~T}_{2}$ and $\mathrm{T}_{3}$. The rats were anesthetized with $2 \%$ pentobarbital $(0.3 \mathrm{ml} / 100 \mathrm{~g}$ body weight, i.p. $)$, perfused through the systemic circulation with cold $0.9 \%$ saline $\left(4^{\circ} \mathrm{C}\right)$ until the backflow fluid in the right atrium was clear, and their eyes and four paws were pale, then perfused through systemic circulation again with $200 \mathrm{ml} \mathrm{4 \%}$ paraformaldehyde (PBS $0.1 \mathrm{M}, \mathrm{pH} 7.4$ ). Then the cerebral cavity was carefully opened and the brain was quickly removed. Approximately $6-\mathrm{mm}$ thick coronal brain tissues were taken with up to 1-2 mm of cerebellum. The coronal brain tissue was immersed in $4 \%$ paraformaldehyde (PBS $0.1 \mathrm{M}, \mathrm{pH} 7.4$ ) and stored at $4{ }^{\circ} \mathrm{C}$ for $24 \mathrm{~h}$. Coronal brain slices containing hippocampus of about 5-mm thick were cut and embedded in paraffin. The brain slices were sequentially cut into $4-\mu \mathrm{m}$ thick sections for further immunohistochemical staining and hematoxylin and eosin staining (HE).

\section{Pyramidal Cell Morphology and Cell Count Detection}

Half of the aforementioned 4- $\mu \mathrm{m}$ thick sections were stained with HE for light microscope observation. The CA1 area of the hippocampus from each animal was captured and Imaging-Pro-Plus (Leica DMLB, Solms, Germany) was used to perform cell number quantitative analysis. Histological changes in the $\mathrm{CA}_{1}$ hippocampus sections were evaluated by a blind rater under an optical microscope. Four fields $(\times 400)$ were sequentially selected for each section, and the numbers of pyramidal cells present inside were counted. Normal pyramidal cells have relatively big cell body, rich in cytoplasm, with one or two big round nuclei. In contrast, damaged cells show shrunken cell body, condensed nuclei, dark cytoplasm, and many empty vesicles.

\section{Immunohistochemical Staining}

The remaining half of the $4-\mu \mathrm{m}$ thick sections underwent standard immunohistochemical staining. The slices were incubated with $3 \% \mathrm{H}_{2} \mathrm{O}_{2}, 3 \%$ normal goat serum and incubated with primary antibodies in $0.01 \mathrm{~mol} / 1$ phosphatebuffered saline at $4{ }^{\circ} \mathrm{C}$ overnight. Rabbit anti-rat NF- $\kappa \mathrm{B}$ p65 antibody (1:50, Cell Signaling Technology, USA), and rabbit anti-rat IgG-HRP antibody (1:100, Cell Signaling Technology, USA) were used. Immunohistochemistry was performed via the avidin biotin technique, and hematoxylin was selected as counterstaining. The secondary antibodies, secondary biotinylated conjugates and diaminobenzidine were from the SP rabbit kit (Cowin Biology Technology Company, China). An examiner blinded to the experimental groups counted the NF- $\mathrm{BB}$ positive cells under a BX53 light microscope (Olympus, Japan). For each sample, four fields $(\times 400)$ were sequentially selected for each section, and the numbers of positive cells were counted. The average positive cells of each slice were obtained by dividing the sum of the positive cells counted from each field by four. The average of each sample was used for statistical analysis.

\section{Preparation of Hippocampus Tissues}

At $24 \mathrm{~h}$ reperfusion, three rats were anesthetized (10\% chloral hydrate, $400 \mathrm{mg} / \mathrm{kg}$, i.p), and systemic circulation was perfused with $0.9 \%$ saline on ice until their eyes and paws were pale. The rats cerebral cavity was carefully opened, and the hippocampus was immediately removed. Hippocampus tissue was homogenized with 9 volumes of $4{ }^{\circ} \mathrm{C}$ saline 
into $10 \%$ tissue homogenate and centrifuged at $3000 \times g$ for $20 \mathrm{~min}$. The supernatant was collected for TNF- $\alpha$ detection.

\section{Total RNA Isolation and Real-Time RT-PCR}

Four rats in each group were used for miRNA analysis. The hippocampus was lysed and total mRNA was isolated using the Trizol reagent, according to the manufacturer's protocol (Life Technologies Corporation, Netherlands). Total mRNA was reverse-transcribed into cDNA using RevertAid first Strand cDNA Synthesis Kit (Invitrogen, Frederick, MD, USA) for Quantitative PCR (TaKaRa Bio Group, Japan) in the presence of a fluorescent dye (SYBR Green I, Cwbio). miR-210 and miR-21 were reverse-transcribed and PCR primers were designed in reference to the method of Chen et al. [27, 28]. U-87 was used as an internal reference. RTqPCR was used to analyze miR-210 and miR-21 expressions at 6, 24 and $96 \mathrm{~h}$. Primer sequences were as follows:

miR-210 Rt-PCR primer: GTCGTATCCAGTGCAGGG TCCGAGGTATTCGCACTGGATACGACTCAGCC; upstream primer: AGCGTGCTGTGCGTGTGAC; downstream primer: CAGTGCAGGGTCCGAGGTAT $\mathrm{T}$. The length of amplified products was $64 \mathrm{bp}$. miR-21 Rt-PCR primer: GTCGTATCCAGTGCAGGGT CCGAGGTATTCGCACTGGATACGACTCAACA; ipstream primer: GCCGCGTAGCTTATCAGACT; downstream primer: CAGTGCAGGGTCCGAGGTATT. The length of amplified products was $61 \mathrm{bp}$. U87 Upstream primer: ACAATGATGACTTATGTT TTT; downstream primer: GCTCAGTCTTAAGATTCT $\mathrm{CT}$. The length of amplified products was $72 \mathrm{bp}$.

\section{Flow Cytometry Analysis}

Blood samples of four rats were collected at $T_{0}, T_{1}, T_{2}$ and $\mathrm{T}_{3}$ for cell population analysis by flow cytometry. Venous blood (approximately $50 \mu \mathrm{l}$ ) was harvested from the eyes of anesthetized rats and collected in heparinized tubes. All blood samples were washed once in phosphate-buffered saline (PBS) containing 1\% fetal calf serum (FCS) and stained with the following combination of fluorescently labeled anti-mouse monoclonal antibodies (eBioscience, San Diego, CA, USA): anti-CD4 and anti-CD25 for $15 \mathrm{~min}$. After surface staining, the samples were permeabilized by incubation with the fixation/permeabilization buffer (eBioscience, San Diego, CA, USA) and incubated with anti-Foxp3 monoclonal antibody (mAbs) for $30 \mathrm{~min}$. After incubation with anti-Foxp3, cells were analyzed by flow cytometry using a Becton Dickinson (BD) FACS Caliber and Cell Quest Software (BD Biosciences, San Jose, CA, USA). Isotype-matched antibodies were used as controls for all samples.

\section{Splenocyte Culture In Vitro}

Spleens were harvested simultaneously with blood samples under sterile conditions. A single-cell suspension was prepared by passing the tissue through a $200 \mu \mathrm{m}$ nylon mesh screen. The filtrate was washed using RPMI 1640 (GibcoInvitrogen, Carlsbad, CA, USA) and then centrifuged to remove the supernatant. Red cells in the centrifuged sample were lysed using red cell lysis buffer and the supernatant obtained by centrifugation (1200 rev/min) was removed. Red blood cells were removed from splenocytes then washed with RPMI 1640 , counted and adjusted to $5 \times 10^{6}$ cells/ml in RPMI medium, which we called spleen blood mononuclear cell (SBMC) [29]. SBMC were filtered in a sterile nylon column and the opaque filtrate was harvested in culture plates. The culture plates were incubated for $72 \mathrm{~h}$ at $37^{\circ} \mathrm{C}$ and $5 \% \mathrm{CO}_{2}$. After 3 days, the supernatants were harvested and stored at $-80^{\circ} \mathrm{C}$ for cytokines detection by ELISA assay.

\section{Enzyme-Linked Immunosorbent Assay}

Quantitative TGF- $\beta 1$ level determination in the spleen and TNF- $\alpha$ in the hippocampus were evaluated using a standard ELISA according to the manufacturer's instructions (ELISA Set, R\&D Systems). Values were expressed in $\mathrm{pg} / \mathrm{ml}$. Optical density was measured at $450 \mathrm{~nm}$ within $10 \mathrm{~min}$ and protein concentrations were determined using a provided standard curve.

\section{Statistical Analysis}

Data were expressed as the mean \pm SD. Statistical analysis was carried out using the SPSS Statistics 13.0 (SPSS Inc., Chicago, IL, USA). Differences between multiple groups were analyzed by the one-way analysis of variance (ANOVA). Changes between experimental groups were determined by the Dunnett's T3 post hoc test. Bivariate analysis was performed to evaluate the reliability of miR210 , miR-21, Treg, TGF- $\beta 1$, NF- $\mathrm{kB}$, TNF- $\alpha$ and the cerebral ischemia-reperfusion injury severity; the correlation coefficient was $r$. A value of $P<0.05$ was considered statistically significant.

\section{Results}

\section{HRS Reduced Global Cerebral I/R Damage}

To investigate the effect of HRS on the global cerebral $\mathrm{I} / \mathrm{R}$ in rats, behavioral test at $\mathrm{T}_{1}, \mathrm{~T}_{2}$ and $\mathrm{T}_{3}$, qualitative and quantitative analysis of pyramidal cell were performed at $\mathrm{T}_{0}, \mathrm{~T}_{1}, \mathrm{~T}_{2}$ and $\mathrm{T}_{3}$. Compared with the sham and sham $+\mathrm{H}_{2}$ 
groups, NSS increased in both $\mathrm{I} / \mathrm{R}$ and $\mathrm{H}_{2}$ groups at each time point after reperfusion. However, the NSS in the I/R group was higher than $\mathrm{H}_{2}$ group at $\mathrm{T}_{2}$ and $\mathrm{T}_{3}(P<0.05)$ (Fig. 1a). Indeed, the $\mathrm{I} / \mathrm{R}$ group showed a time-dependent NSS increase, while the $\mathrm{H}_{2}$ group showed a NSS increase at $\mathrm{T} 1$ followed by a decrease at $\mathrm{T} 2$ and $\mathrm{T} 3(P<0.05)$.

The pyramidal cells in the $\mathrm{CA}_{1}$ area of the hippocampus of the rats belonging to the sham and sham $+\mathrm{H}_{2}$ groups were close to each other and neatly arranged. Compared with the sham and sham $+\mathrm{H}_{2}$ groups, the cells in the $\mathrm{CA}_{1}$ area of the hippocampus of the $\mathrm{I} / \mathrm{R}$ group revealed occasional nuclear atypia at $6 \mathrm{~h}$ after reperfusion although the cell arrangement was still the usual one of the controls. However, at $24 \mathrm{~h}$ after reperfusion the pyramidal cells were loosely arranged and the number of dead cells was increased. At $96 \mathrm{~h}$ after reperfusion the pyramidal cells showed a large number of intracellular vacuoles and they are sparsely arranged, their nuclei were condensed. On the other hand, the cells in the $\mathrm{CA}_{1}$ area of the hippocampus of the $\mathrm{H}_{2}$ group were closely and neatly arranged at $6 \mathrm{~h}$ after reperfusion. At $24 \mathrm{~h}$ after
Fig. 1 Hydrogen-rich saline (HRS) reduces brain injury after global cerebral $I / R$ in rats. a NSS is increased at the three time points after $\mathrm{I} / \mathrm{R}$ vs the Sham and Sham $+\mathrm{H}_{2}$ groups. HRS decreased brain injury at 24 and $96 \mathrm{~h}$. ${ }^{*} \mathrm{P}<0.05 \mathrm{vs}$ sham and $\mathrm{Sham}+\mathrm{H}_{2}$ groups, ${ }^{\#} \mathrm{P}<0.05$ vs I/R group. Values are expressed as mean $\pm \mathrm{SD}$, $\mathrm{n}=14$. b Pyramidal cells in the $\mathrm{CA}_{1}$ area of rat hippocampus from the four treatment groups at different time points. $\mathbf{c}$ The number of pyramidal cells in the CA1 area of the hippocampus at 6,24 , and $96 \mathrm{~h}$ after $\mathrm{I} / \mathrm{R}$ with or without HRS; $* \mathrm{P}<0.05$ vs Sham and Sham $+\mathrm{H}_{2}$ groups, ${ }^{\#} \mathrm{P}<0.05$ vs I/R group. Values are expressed as mean $\pm \mathrm{SD}$, $\mathrm{n}=3$
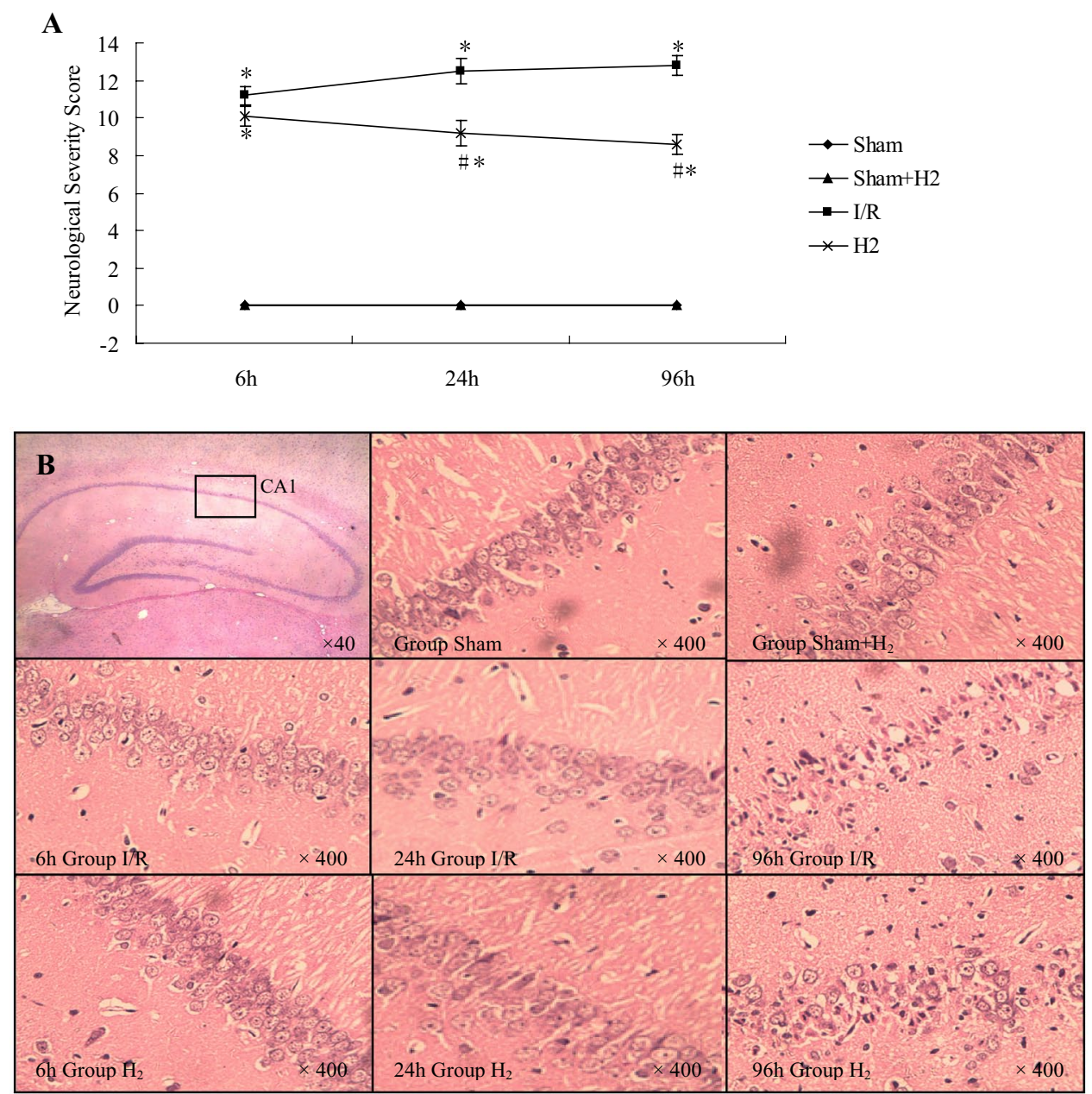

C

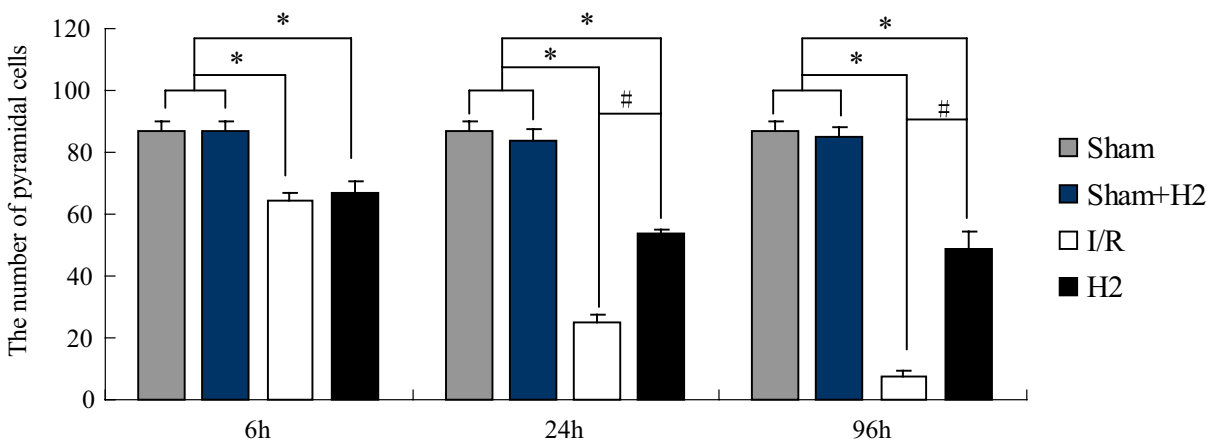


reperfusion, sporadic pyramidal cell death was observed while the arrangement was still the usual one of the controls. At $96 \mathrm{~h}$ after reperfusion some pyramidal cells showed karyopyknosis and cell death was increased, although a normal arrangement of the pyramidal cells was still visible and the cell damage was less prominent than the $\mathrm{I} / \mathrm{R}$ group at 96 h (Fig. 1b).

Compared with the sham and sham $+\mathrm{H}_{2}$ groups, the number of pyramidal cells in the $\mathrm{CA}_{1}$ area of the hippocampus at 6,24 and $96 \mathrm{~h}$ after reperfusion in both the $\mathrm{I} / \mathrm{R}$ and $\mathrm{H}_{2}$ group was significantly decreased $(P<0.05)$ in a time-dependent manner. On the other hand, the cell number in group $\mathrm{H}_{2}$ was significantly higher at 24 and $96 \mathrm{~h}$ after reperfusion compared with the I/R group $(P<0.05)$ (Fig. 1c).

\section{HRS Regulated miR-210 and miR-21 in the Hippocampus After I/R}

Since increasing evidence suggests that miRNA expression profile in cerebral $\mathrm{I} / \mathrm{R}$ injury changes significantly, miR210 and miR-21 in the hippocampus were measured at 6 , 24 and $96 \mathrm{~h}$ after reperfusion. Compared with the sham and sham $+\mathrm{H}_{2}$ groups, miR-210 and miR-21 expression in group I/R was significantly increased at 24 and $96 \mathrm{~h}$ after reperfusion $(P<0.05)$, while miR-210 and miR-21 expression in group $\mathrm{H}_{2}$ was significantly decreased at 24 and $96 \mathrm{~h}$ compared with group I/R $(P<0.05)$ (Fig. 2). The expression of miR-210 and miR-21 in all groups was negatively correlated with the pyramidal cells number in the $\mathrm{CA}_{1}$ area of the hippocampus at $24 \mathrm{~h}$ after reperfusion $(P<0.05$, Pearson correlation coefficient $r=-0.65$ and $P<0.05, r=-0.84$, respectively).

\section{HRS Influenced Immune System Response After I/R}

To determine whether HRS could influence the immune system response after global cerebral $\mathrm{I} / \mathrm{R}$ in rats, regulatory $\mathrm{T}$ cells in the periphery and the concentration of spleen TGF$\beta 1$ from each group were evaluated at 6,24 and $96 \mathrm{~h}$ by flow cytometry and ELISA. Compared with the sham and sham $+\mathrm{H}_{2}$ groups, the Treg cell population was decreased in the $\mathrm{I} / \mathrm{R}$ group at $\mathrm{T}_{1}, \mathrm{~T}_{2}$ and $\mathrm{T}_{3}$ time points $(P<0.05)$. The Treg cell population was decreased in the $\mathrm{H}_{2}$ group at $\mathrm{T}_{1}$ time point $(P<0.05)$, compared with group I/R Treg cell population that was increased at $\mathrm{T}_{2}$ and $\mathrm{T}_{3}$ time points in group $\mathrm{H}_{2}$ $(P<0.05)$ (Fig. 3a, b). TGF- $\beta 1$ expression was decreased in the $\mathrm{I} / \mathrm{R}$ group at $\mathrm{T}_{1}, \mathrm{~T}_{2}$ and $\mathrm{T}_{3}$ time points compared with the sham and sham $+\mathrm{H}_{2}$ groups $(P<0.05)$. TGF- $\beta 1$ expression was increased at $\mathrm{T}_{2}$ and $\mathrm{T}_{3}$ time points in the $\mathrm{H}_{2}$ group compared with the I/R group $(P<0.05)$ (Fig. $3 \mathrm{c})$. Treg were positively correlated with TGF- $\beta 1$ expression in all the groups $(P<0.05, r=0.607)$. NF- $\mathrm{\kappa B}$ expression in the hippocampus (an important pro-inflammatory mediator), and TNF- $\alpha$ concentrations in the hippocampus from each group were evaluated at $24 \mathrm{~h}$ by immunohistochemical staining and ELISA. NF- $\mathrm{kB}$ positive cell numbers in the CA1 area
Fig. 2 MicroRNA-21 and MicroRNA-210 expression are altered in the hippocampus after I/R. a miR-21 expression by qRT-PCR analysis of total RNA isolated from hippocampal tissue harvested at the indicated times after injury. miR-21 expression in the hippocampus at 6,24 , and $96 \mathrm{~h}$ after $\mathrm{I} / \mathrm{R}$ with or without HRS; $* \mathrm{P}<0.05$ vs Sham and Sham $+\mathrm{H}_{2}$ groups, ${ }^{\#} \mathrm{P}<0.05$ vs I/R group. Values are $\operatorname{mean} \pm \mathrm{SD}, \mathrm{n}=4$. b miR210 expression by qRT-PCR analysis in the hippocampus at the indicated times after injury. $* \mathrm{P}<0.05$ vs Sham and Sham $+\mathrm{H}_{2}$ groups, ${ }^{\#} \mathrm{P}<0.05$ vs $\mathrm{I} / \mathrm{R}$ group. Values are expressed as mean $\pm \mathrm{SD}, \mathrm{n}=4$

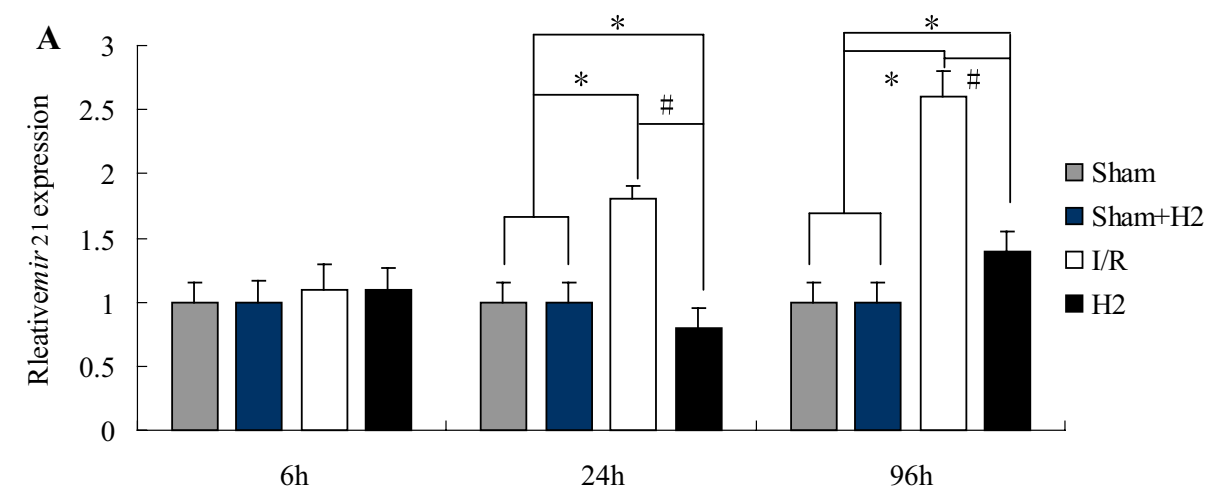

B

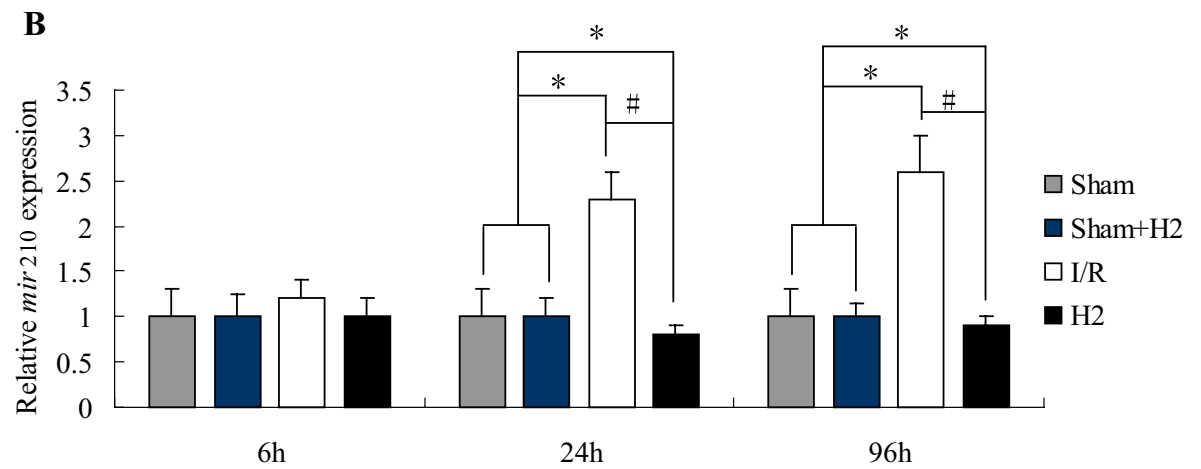


Fig. 3 Regulatory T cells in the periphery and TGF- $\beta 1$ spleen level in each group were respectively evaluated by flow cytometry and ELISA. a Treg cell numbers at 6,24 , and $96 \mathrm{~h}$ after I/R with or without HRS; $* \mathrm{P}<0.05$ vs Sham and Sham $+\mathrm{H}_{2}$ groups, ${ }^{\#} \mathrm{P}<0.05$ vs I/R group. Values are mean $\pm S D, n=4$. b Flow cytometry assay at $24 \mathrm{~h}$ after I/R. c TGF- $\beta 1$ in the spleen at 6,24 , and $96 \mathrm{~h}$ after $\mathrm{I} / \mathrm{R}$ with or without HRS; $* \mathrm{P}<0.05$ vs Sham and $\mathrm{Sham}+\mathrm{H}_{2}$ groups, ${ }^{\#} \mathrm{P}<0.05$ vs $\mathrm{I} / \mathrm{R}$ group. Values are expressed as mean $\pm \mathrm{SD}, \mathrm{n}=4$

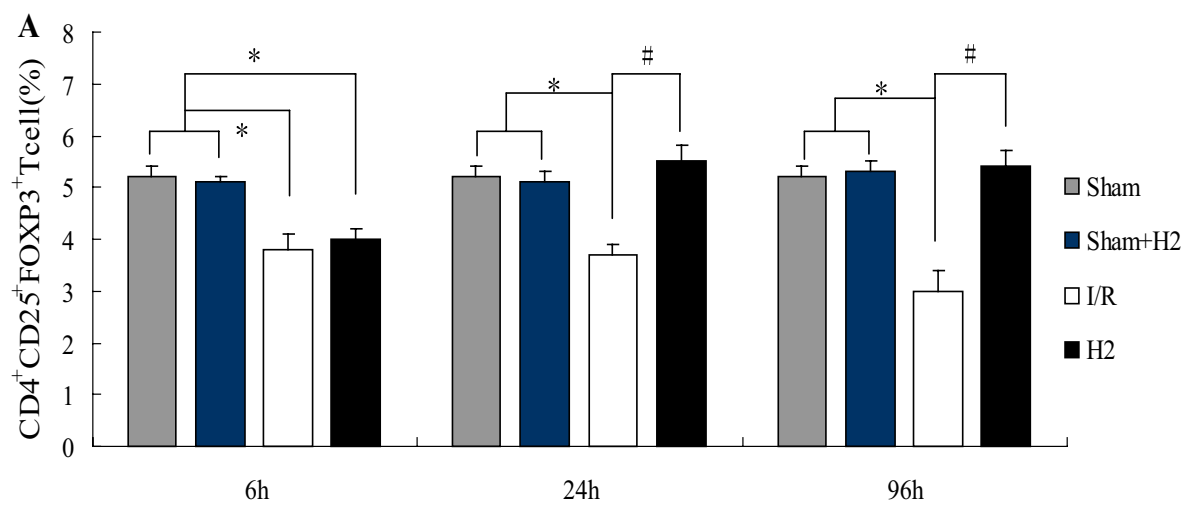

B 24h Sham

$24 \mathrm{~h} \mathrm{Sham}+\mathrm{H}_{2}$

$24 \mathrm{~h}_{2}$

$24 \mathrm{~h} \mathrm{I} / \mathrm{R}$
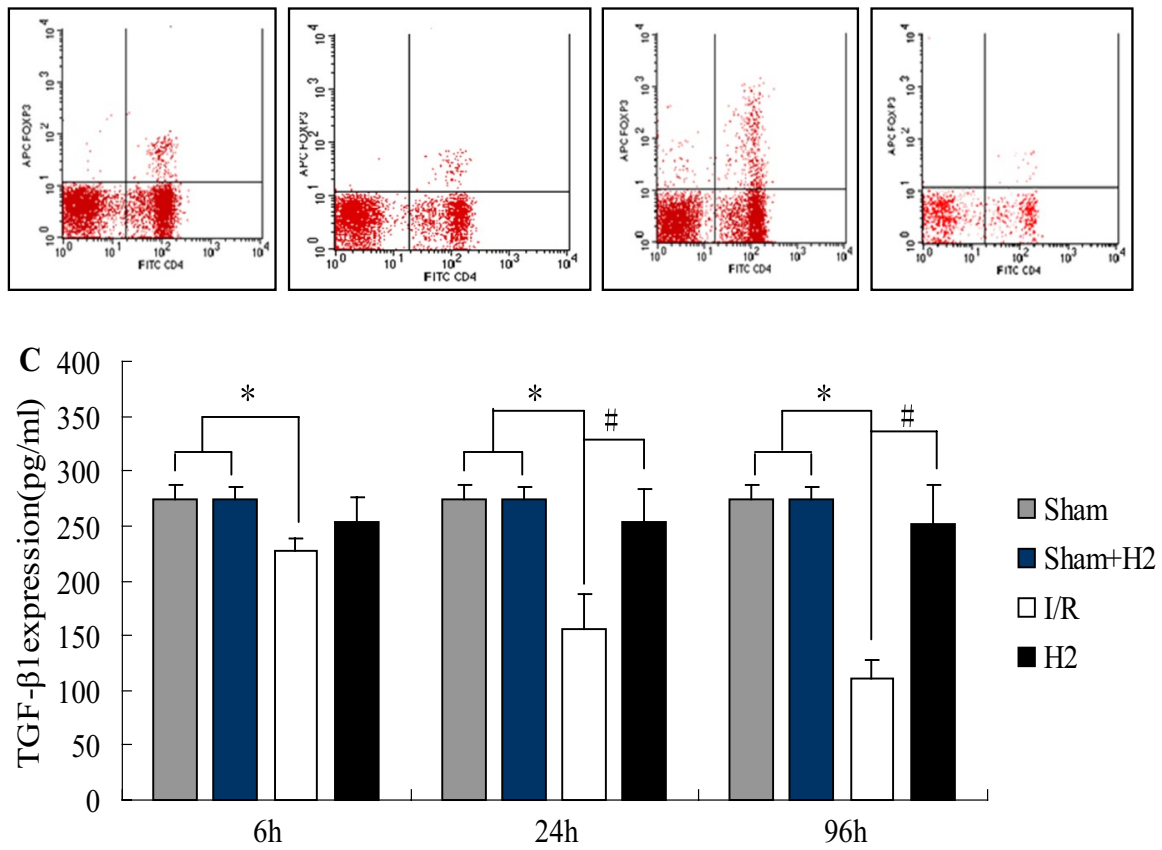

of the hippocampus at $24 \mathrm{~h}$ in the $\mathrm{H}_{2}$ group were higher than the sham and sham $+\mathrm{H}_{2}$ groups, but significantly lower than the I/R group $(P<0.05$, Fig. $4 \mathrm{a}, \mathrm{b})$. TNF- $\alpha$ concentrations at $24 \mathrm{~h}$ in the hippocampus of the $\mathrm{H}_{2}$ group were also higher than in the sham and sham $+\mathrm{H}_{2}$ groups but significantly lower than in the I/R group $(P<0.05$, Fig. $4 \mathrm{c})$.

\section{Discussion}

\section{HRS Reduced I/R Brain Injury}

Hydrogen is a potent free radical scavenger that is thought to induce protective effects through anti-oxidative stress and apoptotic pathways. Our previous studies demonstrated that hydrogen $\left(\mathrm{H}_{2}\right)$ reduced radiation-induced caspase- 3 and Bax activation, and enhanced bcl-2 levels after cerebral I/R $[10,30]$. We also demonstrated that intraperitoneal injection of HRS at $6 \mathrm{~h}$ after cerebral I/R was more efficient than an intraperitoneal injection during reperfusion. Some researchers have found that immediately after cerebral ischemia and reperfusion, cellular oxidative phosphorylation capacity was reduced, inflammatory cells were activated, large amounts of inflammatory cytokines and reactive oxygen species were released, then inflammatory cytokines in the brain tissue peaked at $6 \mathrm{~h}$ after reperfusion $[31,32]$. In this study, we choose to perform a HRS intraperitoneal injection immediately after reperfusion and $6 \mathrm{~h}$ after reperfusion to treat cerebral I/R injury in rats.

Cerebral I/R can cause serious neuronal injury and death, which can further lead to learning and memory impairment and neurodegeneration. The pyramidal neurons in the CA1 area of the hippocampus are essential for spatial learning and memory functions. When suffering from cerebral ischemia insult, the hippocampal pyramidal neurons are the most vulnerable to the reduction of blood supply to the 
Fig. 4 NF-кB immunohistochemical staining and positive cell counts, and TNF- $\alpha$ concentration in the hippocampus. a $\mathrm{NF}-\mathrm{kB}$ immunohistochemical staining in the hippocampus in rats at $24 \mathrm{~h}$ after I/R. b NF- $\mathrm{KB}$ positive cell counts in the CA1 area of the hippocampus at $24 \mathrm{~h}$ after reperfusion. $* \mathrm{P}<0.05 \mathrm{vs}$ Sham and Sham $+\mathrm{H}_{2}$ groups, ${ }^{\#} \mathrm{P}<0.05 \mathrm{vs} \mathrm{I} / \mathrm{R}$ group. Values are mean $\pm \mathrm{SD}, \mathrm{n}=3$. $\mathbf{c} \mathrm{TNF}-\alpha$ concentration in the hippocampus at $24 \mathrm{~h}$ after reperfusion. $* \mathrm{P}<0.05$ vs sham group, ${ }^{\#} \mathrm{P}<0.05 \mathrm{vs} \mathrm{I} / \mathrm{R}$ group. Values are expressed as mean $\pm \mathrm{SD}$, $\mathrm{n}=3$

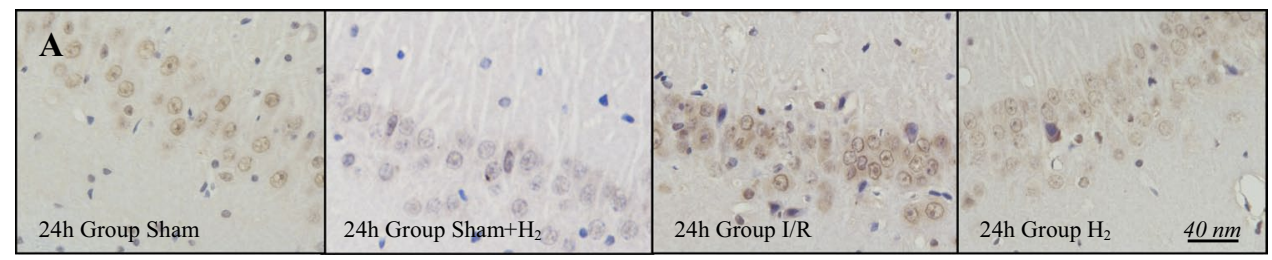

B

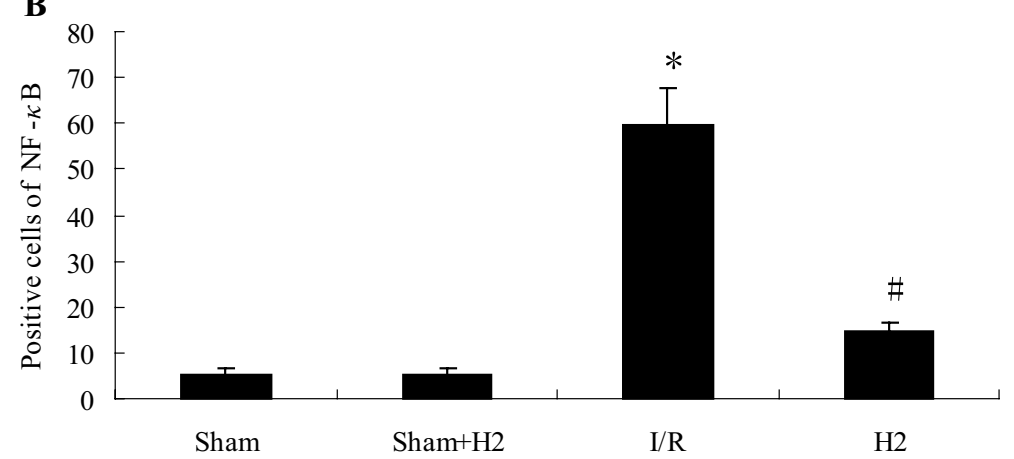

C

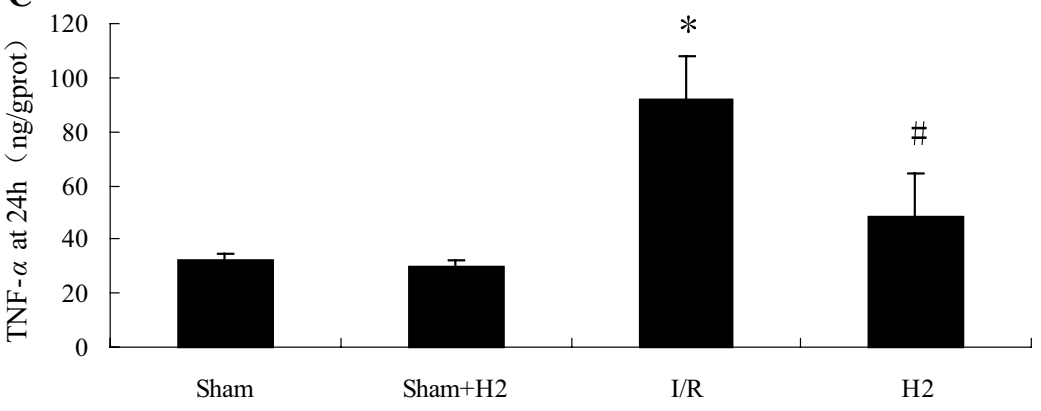

brain, and cell death occurs days after the initial ischemic insult, a phenomenon termed "delayed neuronal death" [33]. Currently, the mechanisms of neuronal injury and death induced by cerebral I/R are not completely known, and therefore an effective therapy for ischemic cerebral damage has remained elusive. In this study, HRS significantly increased the number of surviving cells in the rats $I / R$ CA1 area of the hippocampus compared with the I/R group. Similarly, the test of neurobehavioral test confirmed that HRS reduced I/R brain injury. This protective effect could be due to the diffusion rate of HRS. Indeed, hydrogen has a good diffusion rate, can easily penetrate the blood-brain barrier, and reach the deep brain tissue, and it is also able to reach the site of injury before revascularization to remove toxic oxygen free radicals [34].

\section{HRS Modulated miR-210 and miR-21 Expression}

Ischemia disrupts the balance between endogenous oxidants and antioxidants and overproduces toxic free radicals, thus plenty of ROS are generated during an acute ischemic stroke. Reperfusion also comes with massive production of reactive oxygen species (ROS) and reactive nitrogen species (RNS) that potentiate initial brain injury. Hydroxyl radicals easily react with DNA, proteins and lipids, to evoke disastrous cytotoxic effect [32].

Studies have reported that miRNA is involved in the process of cellular responses to hypoxia. In recent years, many independent studies have demonstrated that the expression of a specific set of miRNA is upregulated by hypoxia. These uniquely induced miRNA were termed as "hypoxamirs", and they appear to control a network of multiple processes during the hypoxic response [35]. Many studies have identified miRNA-210 (miR-210) as a unique hypoxamirs that is robustly and ubiquitously induced in both transformed and primary cell types [36, 37]. MiR-21 is an effective antiapoptotic factor and its main function is to act on a specified pro-apoptotic gene. Aberrant miR-21 expression has been reported in traumatic brain injury and increased miR21 expression has been linked to increased cell survival, growth, and proliferation and decreased apoptosis [38, 39]. Our data showed that miR-210 expression was up-regulated after $15 \mathrm{~min}$ ischemia and $6 \mathrm{~h}$ reperfusion, and the elevated miR-210 expression peaked at $96 \mathrm{~h}$ post-injury. The trend of miR-21 expression was similar to that of miR-210. When the cerebral I/R injury was treated with HRS immediately after reperfusion, miR-210 and miR-21 expressions were decreased significantly at 24 and $96 \mathrm{~h}$. Our results of an 
increased miR-210 and miR-21 after I/R injury and their decrease in the HRS treated rats, together with the histological examination and behavioral test results shown in our study, suggested that miR-210 and miR-21 may be considered markers of cerebral I/R injury.

\section{HRS Regulated Immune System Response After I/R}

Originally thought to be completely separated from the peripheral immune system, it is now recognized that activated immune cells can access the brain without requiring local trauma [25]. The mechanisms that regulate the immunity response after cerebral ischemia are multiple. An important component of the mechanisms is the overactive immune responses that can lead to CNS damage with wide and far-reaching consequences to survival [40]. Therefore, it is vitally important to maintain the immune balance to reduce brain damage. The spleen is an important immune organ that consists of aggregates of lymphoid tissue [41], and therefore was chosen for analysis of representative immunological functions in this study. Regulatory $\mathrm{T}$ cells (Tregs) are antigen specific, possessing T-cell receptors, and they possess a suppressive function. Indeed, they modulate the immune system, maintain tolerance to self-antigens, abrogate autoimmune disease and suppress immune responses of other cells [42]. This is an important "selfcheck" built into the immune system to prevent excessive reactions. In rats and human, Treg cells are mainly distributed in the peripheral blood and spleen, with a percentage of approximately $5-10 \%$ peripheral $\mathrm{CD}^{+} \mathrm{T}$ cells [43]. In this experiment, Treg cells number in the rats after $\mathrm{I} / \mathrm{R}$ decreased significantly at different time points. It is noteworthy that Treg cells number continuously declined in the I/R group while markedly increased in the rats treated with HRS at $24 \mathrm{~h}$ after reperfusion. We hypothesized that at reperfusion $24 \mathrm{~h}$, the vivo immune suppression on the rise in rats treated with HRS. The suppression of an overactive immune response can reduce CNS damage.

TGF- $\beta_{1}$ is an important immunomodulatory cytokine, which has a strong immunosuppressive activity. Experiments in vivo and in vitro confirmed that TGF- $\beta_{1}$ can significantly reduce nerve cells death and palliate inflammatory injury after cerebral ischemia. Treg cells can secrete TGF- $\beta_{1}$ while TGF- $\beta_{1}$ can down-regulate Treg cells to suppress T cell responses and maintain immune tolerance [44]. In this experiment, the number of Treg cells and TGF- $\beta 1$ expression were positively correlated, which also confirmed the relationship between Treg and TGF- $\beta 1$.

Ischemia/reperfusion disrupts the balance between systemic immunity and reactive inflammatory cytokines, thus free radicals/oxidants released by inflammatory cells can severely threaten tissue viability in the brain. Inflammatory cytokines play important roles in the neuropathology of brain I/R injury, and the reduction of inflammation was correlated with neuroprotective effects [45]. A study by Tian et al., reported that HRS treatment of TBI (traumatic brain injury)-challenged rats decreased the levels of pro-inflammatory cytokines (TNF- $\alpha$, IL-1 $\beta$ and HMGB1), inflammatory cell numbers (Iba1) and inflammatory metabolites (Cho) and increased the levels of an anti-inflammatory cytokine (IL-10) in the brain tissues of TBI-challenged rats [18]. In this study, $\mathrm{NF}-\kappa \mathrm{B}$ in the hippocampus as an important pro-inflammatory mediator and TNF- $\alpha$ concentration in the hippocampus were evaluated. During reperfusion, the production of reactive oxygen species increased over a short period, activating NF- $\kappa \mathrm{B}$. Once activated, NF- $\kappa \mathrm{B}$ combines with the gene promoters that are involved in inflammation, leading to the production of inflammatory cytokines, among which the most representative is TNF- $\alpha$ [46]. We found NF- $\kappa \mathrm{B}$ expression and TNF- $\alpha$ concentrations in the hippocampus were significantly reduced by HRS in $I / R$ rats at $24 \mathrm{~h}$ after reperfusion. Simultaneously, the number of Treg cells, as important anti-inflammatory mediators, and TGF$\beta 1$ concentration, as an anti-inflammatory cytokine, markedly increased in the rats treated with HRS compared with the $\mathrm{I} / \mathrm{R}$ group. However, there may be many interactions between the central immunity and the peripheral immunity. HRS suppressive effect on immunity might be related to an immunosuppression effect. The exact mechanism still needs further studies.

Recently, it has been reported that more miRNAs are involved in the regulation of the immune system, demonstrating that miRNAs modulate many aspects of the immune responses such as differentiation, proliferation, cell fate determination, function of immune cells, and cytokine responses, as well as the intracellular signaling pathways [47]. Some miRNAs have the potential to broadly influence the molecular pathways that control the development and function of innate and adaptive immune responses. Some study found that miR-210 was down-regulated in Tregs compared with controls and it has potential target sites in the 3-UTR of FOXP3. FOXP3 expression is negatively regulated by miR-210 direct binding to their two target sites in its 3-UTR [48]. Therefore, further in-depth study about miRNAs and Tregs will be performed.

In summary, the present work provided some evidence in support of the hypothesis that HRS could offer a neuroprotective effect on acute global cerebral I/R damage. In particular, HRS beneficial effects against I/R injury were likely exerted by Treg, TGF- $\beta 1$ up-regulation and miR-21, miR$210, \mathrm{NF}-\kappa \mathrm{B}$ and TNF- $\alpha$ down-regulation. Therefore, HRS provided an effective pharmacological effect of potential therapeutic applications for future treatment of acute global cerebral ischemia and reperfusion. 
Acknowledgments This research was supported by the Medical technology innovation Foundation of Nanjing Military (MS120, 2013), the National Natural Science Foundation of China (No. 81401602), the Medical Technology Foundation of the PLA (No. CNJ13J006) and Medical Foundation of Nanjing General Hospital of Nanjing Military Command (No. 2015069).

\section{Compliance with Ethical Standards}

Conflict of Interest The authors declare that they have no conflict of interest.

Open Access This article is distributed under the terms of the Creative Commons Attribution 4.0 International License (http://creativecommons.org/licenses/by/4.0/), which permits unrestricted use, distribution, and reproduction in any medium, provided you give appropriate credit to the original author(s) and the source, provide a link to the Creative Commons license, and indicate if changes were made.

\section{References}

1. Hotchkiss RS, Strasser A, McDunn JE, Swanson PE (2009) Cell death. N Engl J Med 361:1570-1583

2. Lu L, Tang D, Wang L, Huang LQ, Jiang GS, Xiao XY, Zeng FQ (2012) Gambogic acid inhibits tnf-alpha-induced invasion of human prostate cancer pc 3 cells in vitro through pi3k/akt and nfkappab signaling pathways. Acta Pharmacol Sin 33:531-541

3. Huang Y, Rabb H, Womer KL (2007) Ischemia-reperfusion and immediate T cell responses. Cell Immunol 248:4-11

4. Aggarwal BB (2010) Targeting inflammation-induced obesity and metabolic diseases by curcumin and other nutraceuticals. Annu Rev Nutr 30:173-199

5. Xu WH, Zhang AM, Ren MS, Zhang XD, Wang F, Xu XC, Li Q, Wang J, Din BS, Wu YB, Chen Ghet (2012) Changes of Tregassociated molecules on CD4+ CD25+ Treg cells in myasthenia gravis and effects of immunosuppressants. J Clin Immunol 32:975-983

6. Hou Z, Luo W, Sun X, Hao S, Zhang Y, Xu F, Wang Z, Liu B (2012) Hydrogen-rich saline protects against oxidative damage and cognitive deficits after mild traumatic brain injury. Brain Res Bull 88:560-565

7. Ji X, Tian Y, Xie K, Liu W, Qu Y, Fei Z (2012) Protective effects of hydrogen-rich saline in a rat model of traumatic brain injury via reducing oxidative stress. J Surg Res 178:9-16

8. Mano Y, Kotani T, Ito M, Nagai T, Ichinohashi Y, Yamada K, Ohno K, Kikkawa F, Toyokuni S (2014) Maternal molecular hydrogen administration ameliorates rat fetal hippocampal damage caused by in utero ischemia-reperfusion. Free Radic Biol Med 69:324-330

9. Hayashida K, Sano M, Ohsawa I, Shinmura K, Tamaki K, Kimura K, Endo J, Katayama T, Kawamura A, Kohsaka S, Makino S, Ohta S, Ogawa S, Fukuda K (2008) Inhalation of hydrogen gas reduces infarct size in the rat model of myocardial ischemiareperfusion injury. Biochem Biophys Res Commun 373:30-35

10. Ji Q, Hui K, Zhang L, Sun X, Li W, Duan ML (2011) The effect of hydrogen-rich saline on the brain of rats with transient ischemia. $\mathrm{J}$ Surg Res 168:95-101

11. Hayashida K, Sano M, Kamimura N, Yokota T, Suzuki M, Ohta S, Fukuda K, Hori S (2014) Hydrogen inhalation during normoxic resuscitation improves neurological outcome in a rat model of cardiac arrest independently of targeted temperature management. Circulation 130:2173-2180
12. Fu Y, Ito M, Fujita Y, Ito M, Ichihara M, Masuda A, Suzuki Y, Maesawa S, KajitaY, Hirayama M, Ohsawa I, Ohta S, Ohno K (2009) Molecular hydrogen is protective against 6-hydroxydopamine-induced nigrostriatal degeneration in a rat model of Parkinson's disease. Neurosci Lett 453:81-85

13. Sun H, Chen L, Zhou W, Hu L, Li L, Tu Q, Chang Y, Liu Q, Sun $\mathrm{X}$, Wu M, Wang H (2011) The protective role of hydrogen-rich saline in experimental liver injury in mice. J Hepatol 54:471-480

14. Quero L, Dubois L, Lieuwes NG, Hennequin C, Lambin P (2011) miR-210 as a marker of chronic hypoxia, but not a therapeutic target in prostate cancer. Radiother Oncol 101:203-208

15. Jeyaseelan K, Lim KY, Armugam A (2008) MicroRNA expression in the blood and brain of rats subjected to transient focal ischemia by middle cerebral artery occlusion. Stroke 399:959-966

16. Truettner JS, Alonso OF, Bramlett HM, Dietrich WD (2011) Therapeutic hypothermia alters microRNA responses to traumatic brain injury in rats. J Cereb Blood Flow Metab 31:1897-1907

17. Ji Q, Hui K, Zhang L, Sun X, Li W, Duan M (2011) The effect of hydrogen-rich saline on the brain of rats with transient ischemia. J Surg Res 168:95-101

18. Tian R, Hou Z, Hao S, Wu W, Mao X, Tao X, Lu T, Liu B (2016) Hydrogen-rich water attenuates brain damage and inflammation after traumatic brain injury in rats. Brain Res 1637:1-13

19. Han L, Tian R, Yan H, Pei L, Hou Z, Hao S, Li YV, Tian Q, Liu B, Zhang Q (2015) Hydrogen-rich water protects against ischemic brain injury in rats by regulating calcium buffering proteins. Brain Res 1615:129-138

20. Pulsinelli WA, Buchan AM (1988) The four vessel occlusion rat model method for complete occlusion of vertebral arteries and control of collateral circulation. Stroke 199:13-14

21. Toda S, Ikeda Y, Teramoto A, Hirakawa K, Uekusa K (2002) Highly reproducible rat model of reversible forebrain ischemiamodified four-vessel occlusion model and its metabolic feature. Acta Neurochir 144:1297-1304

22. Liu J, Liu WB, Ji XT, Fei Z, Cheng G (2012) One-stage apertura thoracis superior approach for four-vessel occlusion in rats. Chin J Traumatol 15:13-16

23. Cai J, Kang Z, Liu K, Liu W, Li R, Zhang JH, Luo X, Sun X (2009) Neuroprotective effects of hydrogen saline in neonatal hypoxia-ischemia rat model. Brain Res 1256:129-137

24. Ohsawa I, Ishikawa M, Takahashi K, Watanabe M, Nishimaki K, Yamagata K, Katsura K, Katayama Y, Asoh S, Ohta S (2007) Hydrogen acts as a therapeutic antioxidant by selectively reducing cytotoxic oxygen radicals. Nat Med 13:688-694

25. Chang L, Chen Y, Li J, Liu Z, Wang Z, Chen J, Cao W, Xu Y (2011) Cocaine-and amphetamine-regulated transcript modulates peripheral immunity and protects against brain injury in experimental stroke. Brain Behav Immun 25:260-269

26. Albertsmeier M, Teschendorf P, Popp E, Galmbacher R, Vogel P, Bottiger BW (2007) Evaluation of a tape removal test to assess neurological deficit after cardiac arrest in rats. Resuscitation 74:552-558

27. Chen H, Sun YP, Li Y, Liu WW, Xiang HG, Fan LY, Sun Q, Xu XY, Cai JM, Ruan CP, Su N, Yan RL, Sun XJ, Wang Q (2010) Hydrogen-rich saline ameliorates the severity of 1-arginineinduced acute pancreatitis in rats. Biochem Biophys Res Commun 393:308-313

28. Singhal AB, Lo EH (2008) Advances in emerging nondrug therapies for acute stroke. Stroke 39:289-291

29. Bik W, Skwarlo-Sonta K, Szelagiewicz J, Wolinska-Witort E, Chmielowska M, Martynska L, Baranowska-Bik A, Baranowska B (2008) Involvement of the cocaine-amphetamine regulated transcript peptide (CART55-102) in the modulation of rat immune cell activity. Neuro Endocrinol Lett 29:359-365

30. Cui Y, Zhang H, Ji M, Jia M, Chen H, Yang J, Duan M (2014) Hydrogen-rich saline attenuates neuronal ischemia-reperfusion 
injury by protecting mitochondrial function in rats. J Surg Res 192:564-572

31. Nakao A, Kaczorowski DJ, Wang Y, Cardinal JS, Buchholz BM, Sugimoto R, Tobita K, Lee S, Toyoda Y, Billiar TR, McCurry KR (2010) Amelioration of rat cardiac cold ischemia/reperfusion injury with inhaled hydrogen or carbon monoxide, or both. J Heart Lung Transplant 29:544-553

32. Yin J, Tu C, Zhao J, Ou D, Chen G, Liu Y, Xiao X (2013) Exogenous hydrogen sulfide protects against global cerebral ischemia/ reperfusion injury via its anti-oxidative, anti-inflammatory and anti-apoptotic effects in rats. Brain Res 1491:188-196

33. Lee JC, Kim IH, Park JH, Ahn JH, Cho JH, Cho GS, Tae HJ, Chen BH, Yan BC, Yoo KY, Choi JH, Lee CH, Hwang IK, Cho JH, Kwon YG, Kim YM, Won MH (2015) Ischemic preconditioning protects hippocampal pyramidal neurons from transient ischemic injury via the attenuation of oxidative damage through upregulating heme oxygenase-1. Free Radic Biol Med 79:78-90

34. Jiang Z, Li C, Manuel ML, Yuan S, Kevil CG, McCarter KD, Lu W, Sun H (2015) Role of hydrogen sulfide in early blood-brain barrier disruption following transient focal cerebral ischemia. PLoS One 10:e 0117982

35. Chan SY, Loscalzo J (2010) MicroRNA-210 A unique and pleiotropic hypoxamir. Cell Cycle 9(6):1072-1083

36. Devlin C, Greco S, Martelli F, Ivan M (2011) miR-210: More than a silent player in hypoxia. IUBMB Life 63:94-100

37. Merlo A, de Quiros SB, Secades P, Zambrano I, Balbin M, Astudillo A, Scola B, Aristegui M, Suarez C, Chiara MD (2012) Identification of a signaling axis HIF-1alpha/microRNA-210/ISCU independent of SDH mutation that defines a subgroup of head and neck paragangliomas. J Clin Endocrinol Metab 97:2194-2200

38. Mei Y, Bian C, Li J, Du Z, Zhou H, Yang Z, Zhao RC (2013) miR-21 modulates the ERK-MAPK signaling pathway by regulating SPRY2 expression during human mesenchymal stem cell differentiation. J Cell Biochem 114:1374-1384

39. Liu P, Liang H, Xia Q, Li P, Kong H, Lei P, Wang S, Tu Z (2013) Resveratrol induces apoptosis of pancreatic cancers cells by inhibiting miR-21 regulation of BCL-2 expression. Clin Transl Oncol 15:741-746
40. Harms H, Reimnitz P, Bohner G, Werich T, Klingebiel R, Meisel C, Meisel A (2011) Influence of stroke localization on autonomic activation, immunodepression, and post-stroke infection. Cerebrovasc Dis 32:552-560

41. Miko I, Nemeth N, Sajtos E, Brath E, Peto K, Furka A, Szabo G, Kiss F, Imre S, Furka I (2010) Splenic function and red blood cell deformability: the beneficial effects of spleen autotransplantation in animal experiments. Clin Hemorheol Microcirc 45:281-288

42. Yang R, Qu C, Zhou Y, Konkel JE, Shi S, Liu Y, Chen C, Liu D, Chen Y, Zandi E, Chen W, Zhou Y, Shi S (2015) Hydrogen sulfide promotes Tet1-and Tet2-mediated Foxp3 demethylation to drive regulatory $\mathrm{T}$ cell differentiation and maintain immune homeostasis. Immunity 43:251-263

43. Wang Y, Zhou H, Shen Y, Wang Y, Wu W, Liu H, Yuan Z, Xu Y, Hu Y, Cao J (2015) Impairment of dendritic cell function and induction of $\mathrm{CD} 4(+) \mathrm{CD} 25(+) \mathrm{Foxp} 3(+) \mathrm{T}$ cells by excretorysecretory products: a potential mechanism of immune evasion adopted by Echinococcus granulosus. BMC Immunol 16:44

44. Assadiasl S, Ahmadpoor P, Nafar M, Lessan Pezeshki M, Parvin M, Shahlaee A, Sepanjnia A, Nicknam MH, Amirzargar A (2014) Regulatory $\mathrm{T}$ cell subtypes and TGF-betal gene expression in chronic allograft dysfunction. Iran J Immunol 11:139-152

45. Su Y, Fan W, Ma Z, Wen X, Wang W, Wu Q, Huang H (2014) Taurine improves functional and histological outcomes and reduces inflammation in traumatic brain injury. Neuroscience 266:56-65

46. Yang L, Zhang J, Yan C, Zhou J, Lin Q, Wang W, Zhang K, Yang G, Bian X, Zeng A (2012) sirt1 regulates cd40 expression induced by tnf-alpha via nf-kb pathway in endothelial cells. Cell Physiol Biochem 30:1287-1298

47. Ha TY (2011) The role of microRNAs in regulatory T cells and in the immune response. Immune Netw 11:11-41

48. Fayyad-Kazan H, Rouas R, Fayya-Kazan M, Badran R, Ei Zein N, Lewalle P, Najar M, Hamade E, Jebbawi F, Merimi M, Romero P, Burny A, Badran B, Martiat P (2012) MicroRNA profile of circulating $\mathrm{CD} 4$ positive regulatoryT cells in human adults and impact of differentially expressed microRNAs on expression of two genes essential to their function. J Biol Chem 287:9910-9922 